\title{
Pengaruh Capital Adequacy Ratio, BI7DRR, Inflasi Terhadap Penyaluran Kredit UMKM
}

\author{
Dessy Handa Sari ${ }^{1}$, Rabiatul Annisa ${ }^{2}$, Totok Ismawanto ${ }^{3}$
}

${ }^{123}$ Jurusan Akuntansi, Politeknik Negeri Balikpapan

\begin{tabular}{|c|c|c|}
\hline INFO ARTIKEL & \multicolumn{2}{|c|}{ Abstract } \\
\hline \multirow[t]{2}{*}{$\begin{array}{l}\text { Keywords: } \\
\text { Capital adequacy ratio, BI7DRR, } \\
\text { Inflation and MSME Credit } \\
\text { Distribution }\end{array}$} & \multicolumn{2}{|c|}{$\begin{array}{l}\text { This study aims to measure the effects of the capital adequacy ratio, BITDRR, } \\
\text { and inflation on MSME Credit Distribution to Bank Groups in Indonesia. In } \\
\text { this study, using data sourced from BPS, BI and OJK. It is expected that this } \\
\text { research will contribute to the development of studies, especially MSME credit } \\
\text { distribution. The population of this study is the Bank group in Indonesia. } \\
\text { Regression analysis was carried out to analyze the data in this quantitative } \\
\text { study. This study resulted in the finding that the variable capital adequacy } \\
\text { ratio, BI7DRR, and inflation had a significant effect on credit disbursement at } \\
\text { MSMEs. And partially, the capital adequacy ratio has no effect on MSME } \\
\text { lending. Meanwhile, BI7DRR and inflation have a negative effect on MSME } \\
\text { lending to the Bank Group in Indonesia }\end{array}$} \\
\hline & \multicolumn{2}{|c|}{ Abstraks } \\
\hline $\begin{array}{l}\text { Kata Kunci: } \\
\text { Capital adequacy ratio, BI7DRR, } \\
\text { Inflasi dan Penyaluran Kredit } \\
\text { UMKM } \\
\text { DOI: }\end{array}$ & \multicolumn{2}{|c|}{$\begin{array}{l}\text { Penelitian ini bermaksud untuk mengukur efek dari capital adequacy ratio, } \\
\text { BITDRR, dan inflasi tentang Penyebaran Kredit UMKM pada Kelompok } \\
\text { Bank di Indonesia. Sumber data dalam Penelitian ini berasal dari BPS, BI dan } \\
\text { OJK. Diharapkan dari penelitian ini memberikan kontribusi bagi } \\
\text { pengembangan studi terutama penyaluran kredit UMKM. Fokusan populasi } \\
\text { pada penelitian ini adalah kelompok Bank di Indonesia. Analisis regresi } \\
\text { digunakan untuk menguraikan data kuantitatif dalam penelitian ini. } \\
\text { Penelitian ini memberikan hasil temuan bahwa variabel capital adequacy ratio, } \\
\text { BI7DRR, dan inflasi adanya pengaruh yang saling terkait pada penyaluran } \\
\text { kredit di UMKM. Secara parsial, capital adequacy ratio tidak memberikan } \\
\text { dampak terhadap penyaluran kredit UMKM. Sementara BI7DRR dengan } \\
\text { Inflasi memberikan dampak negative pada penyebaran kredit UMKM di } \\
\text { Kelompok Bank di Indonesia }\end{array}$} \\
\hline \multicolumn{2}{|c|}{$\begin{array}{l}\text { Korespondensi: } \\
\text { Nama: Dessy Handa Sari, Rabiatul Annisa } \\
\text { Email: dessy.handa@poltekba.ac.id }\end{array}$} & $\begin{array}{l}\text { ISSN: 2355-9643(Print) } \\
\text { ISSN:2460-3775(online) }\end{array}$ \\
\hline
\end{tabular}




\section{PENDAHULUAN}

Usaha yang dilakukan oleh masyarakat guna memenuhi kebutuhan sangat beragam, mulai dari bekerja keras sesuai dengan keahliannya ataupun dengan membuat kreatifitas dan inovasi terbaru guna menghasilkan karya yang unik agar memperoleh keuntungan dari hasil karyanya. Usaha Mikro Kecil dan Menengah (UMKM) menjadi wadah dimana memiliki potensi besar guna meningkatkan dan memajukan perekonomian di Indonesia. Salah satu kondisi yang berpengaruh terhadap kebijakan kredit perbankan yaitu inflasi. Karena jika angka inflasi tinggi, maka nilai riil uang akan menurun yang membuat kondisi dimana masyarakat lebih memilih untuk menggunakan uangnya membeli harta tetap seperti rumah maupun tanah.

Menurut (Misral \& Zikra Mardhatillah, 2019), pertumbuhan ekonomi yang terus meningkat saat ini khususnya di Indonesia, membuat para pelaku ekonomi menuntut berbagai cara untuk dapat bertahan dalam menghadapi beberapa permasalahan yang kian menjadi sehingga diperlukan adanya penyesuaian tentang kebijakan ekonomi dan perbaikan sistem keuangan yang telah ada. Usaha yang dilakukan oleh masyarakat guna memenuhi kebutuhan sangat beragam, mulai dari bekerja keras sesuai dengan keahliannya ataupun dengan membuat kreatifitas dan inovasi terbaru guna menghasilkan karya yang unik agar memperoleh keuntungan dari hasil karyanya tersebut.

Berdasarkan data penyaluran kredit UMKM dapat dilihat dari data statistik perbankan Indonesia tentang jumlah rincian kredit UMKM menurut Kelompok Bank yang berkembang di Indonesia. Dapat dilihat dari Gambar 1 yaitu sebagai berikut:

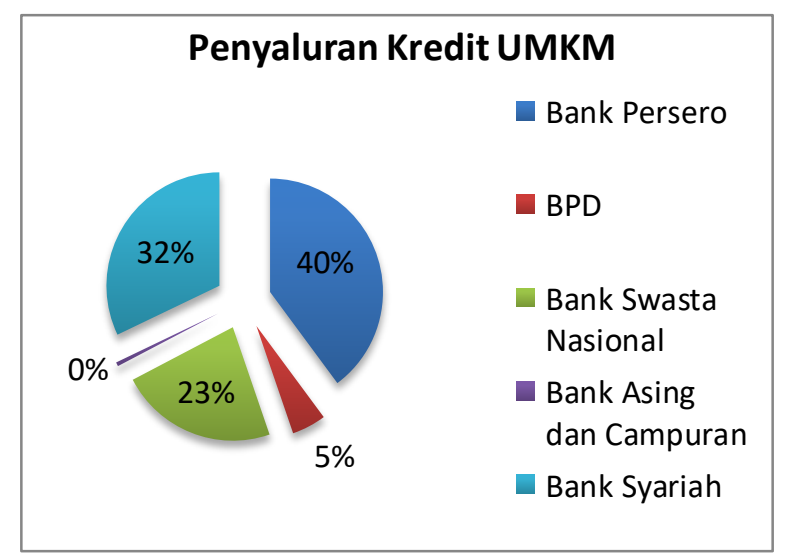

\section{Sumber: ojk.go.id (Statistik Perbankan )}

Berdasarkan grafik diatas, dapat diketahui bahwa sepanjang tahun 2019 penyaluran kredit UMKM menurut berbagai Bank yang ada di Indonesia yang terdiri dari Bank Persero, BPD, Bank Swasta Nasional, Bank Campuran Asing dan Bank Syariah mengalami perbedaan yang cukup siginifikan. Bank Persero dan Bank Syariah memiliki angka penyaluran UMKM terbesar berkisar $40 \%$ pada Bank Persero dan berkisar 32\% untuk Bank Syariah sedangkan yang terkecil bank asing dan campuran. Berdasarkan hal ini, angka tersebut menunjukkan bahwa kredit UMKM yang disalurkan oleh kelompok bank mampu menggerakkan laju perekonomian di kalangan masyarakat.

Kecukupan modal dalam perbankan disebut Capital Adequacy Ratio.Capital Adequacy Ratio merupakan rasio yang membandingkan antara modal terhadap Aktiva Tertimbang Menurut Resiko berdasarkan ketetapan pemerintah (Kasmir, 2014). Angka Capital Adequacy Ratio sebuah perusahaan dapat menjadi pertimbangan untuk melihat kemampuan bank dalam menanggung setiap risiko yang terjadi dari kredit/aktiva.

Faktor penting lainnya yang mempengaruhi dalam mengembangkan UMKM yaitu inflasi, menurut (Antasari \& Akbar, 2019) yaitu kenaikan harga produk maupun jasa yang terjadi secara terus menerus atau dapat diartikan sebagai turunnya nilai uang secara menyeluruh dan dapat mempengaruhi pertumbuhan ekonomi.

BI 7- day Repo Rate (BI7DDR) yakni sebuah startegi dimana bertujuan agar lembaga perbankan dalam menarik dana tidak menunggu dalam jangka waktu setahun, sehingga dalam rentang 7 hari atau kelipatannya bank dapat mengambil uang tersebut. BI telah melakukan penguatan kerangka operasi moneter untuk memberikan pengaruh besar terhadap pasar uang, perbankan serta sektor riil secara tepat dengan mengimplementasikan suku bunga acuan atau suku bunga kebijakan dari BI Rate menjadi BI7DDR (www.bi.go.id).

Menurut (Ratnasari, 2016), dalam penelitiannya, meneliti Variabel yang memberikan pengaruh terhadap Penyaluran Kredit Kepada UMKM menyatakan variabel Inflasi, BI Rate dan Pertumbuhan ekonomi tidak memberikan pengaruh sedangkan CAR 
dan NPL memberikan dampak ke penyaluran kredit UMKM. Secara bersamaan variabel Inflasi, BI Rate, Pertumbuhan Ekonomi, CAR dan NPL berpengaruh terhadap penyaluran kredit UMKM.

Menurut (Jayanti, 2016), dalam penelitiannya tentang Pembiayaan Usaha Mikro Kecil dan Menengah Studi Kasus Pada Bank Umum Syariah yang menyimpulkan bahwa Inflasi dan BI Rate memberikan dampak secara simultan ke pembiayaan UMKM dan untuk secara parsial variabel inflasi berpengaruh positif sedangkan BI Rate tidak memiliki pengaruh terhadap pembiayaan UMKM.

Penulis memfokuskan penelitian pada faktor yang memberikan pengaruh dalam pemberian kredit UMKM yaitu CAR, BI7DRR dan Inflasi. Maka terdapat kerangka pemikiran:

Tabel 1.1 Kerangka Pemikiran

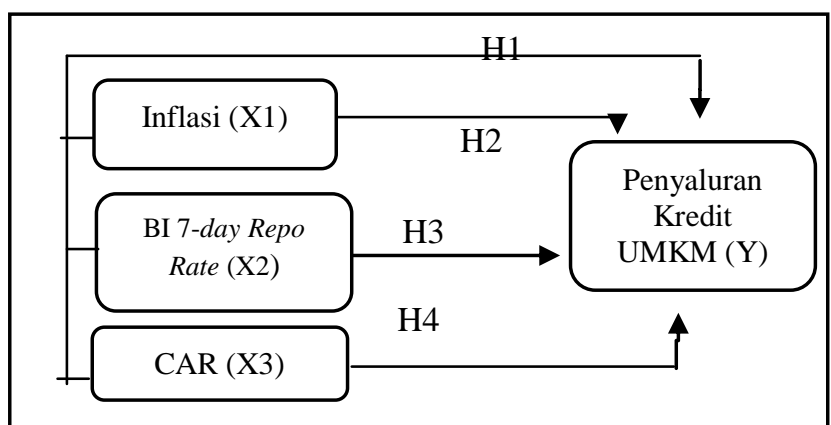

Sumber : Penulis

\section{METODE}

\section{Jenis dan Metode Pengumpulan data}

Penulis menggunakan metode pendekatan kuantitatif (positivis) pada penelitian ini, dengan teknik analisis yang digunakan untuk menguji hipotesis dan menganalisis data yaitu analisis deskriptif, uji asumsi klasik dan uji hipotesis menggunakan analisis regresi linear berganda. Penelitian ini menggunakan analisis linear berganda karena variabel yang diteliti terdapat lebih dari satu variabel

sumber data terkait dengan data inflasi diperoleh dari web resmi Badan Pusat Statistik yaitu www.bps.go.id dan data terkait dengan BI 7-day Repo Rate diambil dari web resmi Bank Indonesia yaitu www.bi.go.id serta data terkait dengan CAR dan UMKM diambil dari web resmi Otoritas Jasa Keuangan (OJK) yaitu www.ojk.go.id.

\section{Populasi dan Sampel}

Menurut Statistik Perbankan Indonesia OJK Bank Umum dibagi menjadi kelompok berdasarkan prinsipnya (konven dan syariah). Kelompok bank berdasarkan prinsip konvensional yaitu Persero, Swasta Nasional, BPD, Asing dan Campuran. Sedangkan bank umum berdasarkan prinsip syariah yaitu Bank Umum Syariah.

Penelitian ini menggunakan kriteria yang mencakup kelompok Bank Umum dengan prinsip konvensional yang ada di Indonesia. Selain itu, variabel independen yang digunakan pada penelitian adalah suku bunga atau BI Rate, hal ini tidak sesuai dengan asas bank umum syariah sehingga kriteria bank yang digunakan sebagai objek yaitu bank umum dengan prinsip konvensional. Data UMKM lengkap menurut kelompok Bank Umum konvensional yang ada di Indonesia terdapat pada situs resmi OJK.

\section{ANALISIS DATA}

Uji Normalitas

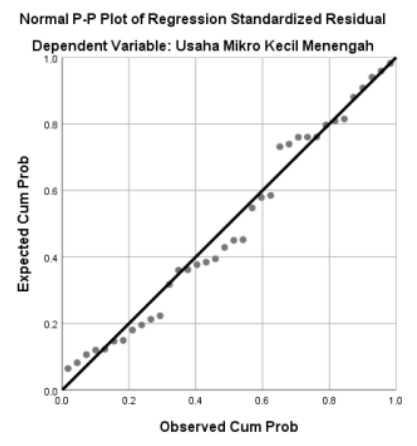

Berdasarkan hasil uji normalitas melalui grafik dapat dilihat bahwa data tersebar disekitar garis diagonal yang artinya data yang ada berdistribusi normal, maka model regresi memenuhi asumsi normalitas.

Uji Multikolonieritas

\begin{tabular}{|c|c|c|c|c|c|}
\hline \multicolumn{6}{|c|}{ Coefficients $^{\mathrm{a}}$} \\
\hline \multirow[b]{2}{*}{ Model } & \multicolumn{2}{|c|}{$\begin{array}{l}\text { Unstandardized } \\
\text { Coefficients }\end{array}$} & \multirow{2}{*}{$\begin{array}{c}\text { Standard } \\
\text { ized } \\
\text { Coefficie } \\
\text { nts }\end{array}$} & \multicolumn{2}{|c|}{$\begin{array}{l}\text { Collinearity } \\
\text { Statistics }\end{array}$} \\
\hline & B & Std. Error & & $\begin{array}{l}\text { Toler } \\
\text { ance }\end{array}$ & VIF \\
\hline $\begin{array}{l}\text { 1(Constan } \\
\text { t) }\end{array}$ & 673737.979 & 245888.670 & & & \\
\hline $\begin{array}{l}\text { Inflasi } \\
\text { BI } 7 \text { Day }\end{array}$ & $\begin{array}{l}3955400.00 \\
7\end{array}$ & $\begin{array}{l}3753418.32 \\
8\end{array}$ & -.329 & .244 & 4.096 \\
\hline Repo Rate & 92717.913 & & .005 & .249 & 4.022 \\
\hline Capital & & 5439713.579 & -.482 & .903 & 1.107 \\
\hline $\begin{array}{l}\text { Adequacy } \\
\text { Ratio }\end{array}$ & $\begin{array}{l}1338724.10 \\
3\end{array}$ & 450234.389 & & & \\
\hline
\end{tabular}

Hasil uji multikolonieritas menunjukkan bahwa nilai Tolerance variabel menunjukkan bahwa tidak terjadi multikolonieritas pada variabel Inflasi, BI7DRR, dan capital adequacy ratio karena nilai Tolerance dan VIF masing- 
masing variabel memenuhi kriteria yakni Tolerance melebihi 0,10 (tidak terjadi multikolonieritas)

\section{Uji Heterokedastisitas}

\begin{tabular}{|c|c|c|c|c|c|}
\hline \multicolumn{6}{|c|}{ Coefficients $^{a}$} \\
\hline \multirow[b]{2}{*}{ Model } & \multicolumn{2}{|c|}{$\begin{array}{c}\text { Unstandardized } \\
\text { Coefficients } \\
\end{array}$} & \multirow{2}{*}{$\begin{array}{c}\begin{array}{c}\text { Standard } \\
\text { ized } \\
\text { Coefficie } \\
\text { nts }\end{array} \\
\text { Beta } \\
\end{array}$} & \multicolumn{2}{|c|}{$\begin{array}{l}\text { Collinearity } \\
\text { Statistics }\end{array}$} \\
\hline & B & Std. Error & & $\begin{array}{l}\text { Toler } \\
\text { ance }\end{array}$ & VIF \\
\hline $\begin{array}{l}\text { 1(Constan } \\
\text { t) } \\
\text { Inflasi } \\
\text { BI 7 Day } \\
\text { Repo Rate } \\
\text { Capital } \\
\text { Adequacy } \\
\text { Ratio }\end{array}$ & \begin{tabular}{|l}
673737.97 \\
9 \\
- \\
3955400.0 \\
07 \\
92717.913 \\
-1338724.1 \\
03
\end{tabular} & \begin{tabular}{|l}
245888.67 \\
0 \\
3753418.3 \\
28 \\
5439713.57 \\
9 \\
450234.389
\end{tabular} & $\begin{array}{r}-.329 \\
.005 \\
-.482\end{array}$ & $\begin{array}{l}.244 \\
.249 \\
.903\end{array}$ & $\begin{array}{l}4.096 \\
4.022 \\
1.107\end{array}$ \\
\hline
\end{tabular}

Berdasarkan hasil pengujian heterokedastisitas setelah data di transform dalam bentuk Ln (logaritma natural) maka dapat diketahui tidak terjadi heterokedastisitas karena variabel Inflasi, BI7DRR dan capital adequacy ratio masing-masing memiliki nilai profitabilitas signifikan diatas tingkat kepercayaan $5 \%$.

Uji Autokorelasi dengan metode First difference

Berdasarkan hasil uji autokolerasi menggunakan pengujian durbin watson, maka diperoleh nilai durbin watson sebesar 2,165. DW berdasarkan tabel $\mathrm{n}=35$ dan $\mathrm{k}=3$ diperoleh nilai $d l=1,2539$ dan $d u=1,6528$. Dengan melihat ketentuan $\mathrm{dl} \leq \mathrm{d} \leq 4-\mathrm{du}$ berikut, sehingga diperoleh hasil yaitu 1,2953 $\leq 2,165 \leq$ 2,3472. Dari hasil tersebut dapat menarik kesimpulan bahwa tidak terjalin autokorelasi positif ataupun negative.

\section{Analisis Regresi Linear Berganda}

\begin{tabular}{|c|c|c|c|c|c|}
\hline \multicolumn{6}{|c|}{ Coefficientsa } \\
\hline \multirow{6}{*}{$\begin{array}{cc}\text { Model } \\
1 \text { (Constant) } \\
\text { Ln@INF } \\
\text { Ln@BI7DRR } \\
\text { Ln@CAR }\end{array}$} & $\begin{array}{l}\text { Unstan } \\
\text { Coeff }\end{array}$ & $\begin{array}{l}\text { ardized } \\
\text { ients } \\
\text { Std. }\end{array}$ & $\begin{array}{l}\text { Standardized } \\
\text { Coefficients }\end{array}$ & & \\
\hline & B & Error & Beta & $\mathrm{T}$ & Sig. \\
\hline & -1.923 & .880 & & - & .037 \\
\hline & -2.066 & .728 & & 2.185 & .008 \\
\hline & 2.775 & 1.011 & -3.362 & - & .010 \\
\hline & -.179 & .446 & $\begin{array}{l}4.522 \\
-.309\end{array}$ & $\begin{array}{l}2.839 \\
2.745 \\
-.400\end{array}$ & 692 \\
\hline
\end{tabular}

Dari hasil analisis dengan menggunakan teknik analisis regresi linear berganda didapatkan persamaaan $\mathrm{UMKM}=-1,923-$ 2,066 (INF) + 2,775 (BI7DRR) - 0,179 (CAR) + e yang berarti setiap kali ada penambahan satuan pada salah satu variabel bebas dengan lainnya diasumsikan sama dengan 0 maka akan menambah nilai penyaluran kredit UMKM atau sebaliknya.

Uji F

\begin{tabular}{|r|r|r|r|c|c|}
\hline \multicolumn{7}{|c|}{ ANOVA $^{\text {a }}$} \\
\hline Model & Sum of & Df & Mean & F & Sig. \\
\hline 1 Regression & 22.038 & 3 & 7.346 & 40.928 & $.000^{\circ}$ \\
\hline
\end{tabular}

Berdasarkan tabel dapat diketahui bahwa nilai $F_{\text {hitung }}$ sebesar 3,379 dan $\mathrm{F}_{\text {tabel }}$ dapat dicari pada tabel statistik signifikansi 5\% atau 0,05. Dapat diketahui bahwa variabel Inflasi, BI 7-day Repo Rate dan capital adequacy ratio memiliki $\mathrm{F}_{\text {hitung }}>$ $\mathrm{F}_{\text {tabel }}(3,379>3,30)$ dan nilai signifikansi 0,000 atau < dari $0,05 \mathrm{H}_{1}$ didapatkan.

Uji Signifikansi Parameter Individual (Uji t)

\begin{tabular}{|c|c|c|c|c|c|}
\hline \multicolumn{6}{|c|}{ Coefficients $^{a}$} \\
\hline \multirow[b]{2}{*}{ Model } & \multicolumn{2}{|c|}{$\begin{array}{l}\text { Unstandardized } \\
\text { Coefficients }\end{array}$} & \multirow{2}{*}{$\begin{array}{c}\begin{array}{c}\text { Standardized } \\
\text { Coefficients }\end{array} \\
\text { Beta }\end{array}$} & \multirow[b]{2}{*}{$\mathrm{T}$} & \multirow[b]{2}{*}{ Sig. } \\
\hline & $\mathrm{B}$ & $\begin{array}{l}\text { Std. } \\
\text { Error }\end{array}$ & & & \\
\hline $\begin{array}{ll}1 & \text { (Constant) } \\
\text { Ln@Inflasi } \\
\text { Ln@BI7DR } \\
\text { R } \\
\text { Ln@CAR }\end{array}$ & $\begin{array}{r}-1.923 \\
-2.066 \\
2.775 \\
-.179\end{array}$ & $\begin{array}{r}.880 \\
.728 \\
1.011 \\
.446\end{array}$ & $\begin{array}{r}-3.362 \\
4.522 \\
-.309\end{array}$ & $\begin{array}{r}- \\
2.185 \\
- \\
2.839 \\
2.745 \\
-.400\end{array}$ & $\begin{array}{l}.037 \\
.008 \\
.010 \\
.692\end{array}$ \\
\hline
\end{tabular}

1. Percobaan pada uji t menunjukkan bahwa niai $t_{\text {hitung }}$ sebesar $-2,839$ sehingga nilai $t_{\text {hitung }}>t_{\text {tabel }}(-2,839>2,03951)$ dan nilai signifikansi sebesar 0,008 atau < dari 0,05 sehingga $\mathrm{H}_{0}$ tidak diterima dan $\mathrm{H}_{1}$ diterima,

2. percobaan pada uji t menunjukkan bahwa niai thitung sebesar 2,745 sehingga nilai $t_{\text {hitung }}$ $>t_{\text {tabel }}(2,745>2,03951)$ dan angka signifikansi sebesar 0,010 atau lebih kecil dari 0,05 maka $\mathrm{H}_{0}$ ditolak dan $\mathrm{H}_{1}$ diterima,

3. Percobaan pada uji $\mathrm{t}$ menunjukkan bahwa memiliki thitung sebesar $-0,400$ sehingga nilai $t_{\text {hitung }}<t_{\text {tabel }} \quad(-0,400<2,03951)$ dan nilai signifikansi sebesar 0,692 atau lebih besar dari 0,05 maka $\mathrm{H}_{0}$ diterima dan $\mathrm{H}_{1}$ ditolak.

\section{Uji Koefisien Determinasi}

\begin{tabular}{|c|c|c|c|c|c|}
\hline \multicolumn{6}{|c|}{ Model Summary } \\
\hline Model & $\mathrm{R}$ & $\begin{array}{c}\mathrm{R} \\
\text { Square }\end{array}$ & $\begin{array}{l}\text { Adjusted } \\
\text { R Square }\end{array}$ & $\begin{array}{c}\text { Std. } \\
\text { Error of } \\
\text { the } \\
\text { Estimate }\end{array}$ & $\begin{array}{l}\text { Durbin- } \\
\text { Watson }\end{array}$ \\
\hline 1 & $.894^{\mathrm{a}}$ & .798 & .779 & .42366 & 2.165 \\
\hline
\end{tabular}

Dari tabel diatas nominal Adjusted R Square sebesar 0,779 atau $77,9 \%$ artinya bahwa variabel Inflasi, BI 7-day Repo Rate dan CAR 
mempengaruhi variabel dependen sebesar $77,9 \%$ dan sisanya $22,1 \%$ dipengaruhi dari variabel lain di luar model regresi.

\section{HASIL DAN PEMBAHASAN}

1. Dari hasil uji regresi linear berganda menunjukan besaran koefisien Inflasi < dari 0,05 sehingga $\mathrm{H}_{0}$ ditolak dan $\mathrm{H}_{1}$ diterima, maka dapat ditarik kesimpulan bahwa Inflasi secara parsial memberikan dampak negatif yang besar terhadap Penyaluran Kredit UMKM pada Kelompok Bank di Indonesia Periode 2011-2019. Hasil penelitian ini menunjukkan bahwa inflasi merupakan variabel makro dimana memberikan dampak dalam penyaluran kredit UMKM. Berdasarkan teori kuantitas dalam Latumaerissa (2015:173) hasil penelitian sesuai dengan teori tersebut yang menyatakan bahwa dalam penelitian ini yaitu inflasi terjadi akibat jumlah uang yang beredar terus meningkat membuat konsumsi masyarakat akan suatu barang menurun sehingga memberikan dampak yakni penurunan jumlah kredit. Apabila inflasi meningkat maka suku bunga kredit akan meningkat, ini terjadi agar menurunkan jumlah uang yang beredar di masyarakat serta mengurangi permintaan kredit masyarakat. Sehingga inflasi memberikan dampak yang negatif terhadap pertumbuhan kredit.

2. Dari hasil uji regresi linear berganda menunjukan besaran koefisien BI 7 day Rapo rate $<$ dari 0,05 maka $\mathrm{H}_{0}$ ditolak dan $\mathrm{H}_{1}$ diterima, maka dapat ditarik kesimpulan bahwa BI 7-day Repo Rate secara parsial memberikan dampak positif yang signifikan terhadap Penyaluran Kredit UMKM pada Kelompok Bank di Indonesia Periode 2011-2019. Berdasarkan teori Keyness dalam (Ambalau et al., 2019) menjelaskan bahwa Teori Keynes merupakan fenomena moneter yang artinya tingkat bunga ditentukan oleh penawaran dan permintaan akan uang (ditentukan dalam pasar uang), hal ini sesuai dengan teori tersebut dikarenakan naik turunnya BI 7-day Repo Rate mempengaruhi penyaluran kredit yang disalurkan oleh setiap kelompok bank. Pengaruh positif yang dimiliki BI 7-day Repo Rate terhadap penyaluran kredit perbankan dikarenakan apabila pada saat terjadinya kenaikan BI 7-day Repo Rate, maka kebutuhan akan dana tambahan baik masyarakat maupun korporasi tetap tinggi, sehingga meskipun secara teori kenaikan tingkat suku bunga akan mempengaruhi minat masyarakat dalam mengajukan kredit akan tetapi tidak menurunkan secara total keinginan masyarakat dan korporasi melakukan pinjaman karena adanya kebutuhan akan dana tambahan tersebut. Dengan demikian BI Rate atau BI 7-day Repo Rate memberikan dampak positif terhadap penyaluran kredit UMKM.

3. Hasil uji regresi linear berganda menunjukan besaran koefisien capital adequacy ratio lebih besar dari 0,05 maka $\mathrm{H}_{0}$ diterima dan $\mathrm{H}_{1}$ ditolak, disimpulkan bahwa capital adequacy ratio secara parsial tidak memiliki pengaruh terhadap Penyaluran Kredit UMKM pada Kelompok Bank di Indonesia. Berdasarkan alasan tidak terdapat pengaruh capital adequacy ratio terhadap penyaluran kredit karena bank lebih memilih untuk menguatkan struktur modalnya daripada menyalurkan modalnya untuk penyaluran kredit karena risiko besar yang harus ditanggung oleh bank ketika melakukan penyaluran kredit. Tidak hanya itu, karena penyaluran kredit saat ini tidak bergantung terhadap peningkatan atau penurunan CAR melainkan kepada kebutuhan masyarakat dan korporasi terhadap kredit.

\section{SIMPULAN}

1. Berdasarkan hasil uji regresi, maka dapat diketahui bahwa variable CAR (capital adequacy ratio), BI7DRR dan Inflasi memberikan pengaruh yang signifikan terhadap penyaluran kredit UMKM. H1 Diterima.

2. Dari uji regresi, maka dapat diperoleh hasil bahwa variabel Inflasi berpengaruh negatif dan signifikan terhadap penyaluran kredit UMKM. H2 Diterima.

3. Dri uji regresi, maka dapat diperoleh hasil bahwa variabel BI7DRR berpengaruh positif dan signifikan terhadap penyaluran kredit UMKM. H3 Diterima.

4. Dari uji regresi, maka dapat diperoleh hasil bahwa variabel CAR (capital adequacy ratio) tidak memberikan pengaruh terhadap penyaluran kredit UMKM. H4 Ditolak. 


\section{DAFTAR PUSTAKA}

Ambalau, P. D., Kumaat, R. J., \& Mandeij, D. (2019). Analisis Pengaruh Jumlah Uang Beredar, Kurs Dan Sibor Terhadap Suku Bunga Pinjaman Bank Umum Melalui Suku Bunga Acuan Bi Periode 2016:M092018:M12. Jurnal Berkala Ilmiah Efisiensi, 19(03), 23-33.

Antasari, W. S., \& Akbar, M. (2019). DAN BI RATE TERHADAP HARGA SAHAM PADA SEKTOR CONSUMER GOOD INDUSTRY GO PUBLIC. Jurnal Manajemen Dan Akuntansi, 20(2).

Jayanti, S. D. (2016). Pengaruh Inflasi dan BI Rate Terhadap Pembiayaan Usaha Mikro Kecil dan Menengah (Studi Kasus Pada Bank Umum Syariah). I-Economics, 2(2), 86-105.

Kasmir. (2014). Analisis Laporan Keuangan (Edisi Revi). PT. Rajagrafindo Persada.

Misral, \& Zikra Mardhatillah, A. (2019). Pengaruh Jumlah Dana Pihak Ketiga (Tabungan dan Deposito) dan Non Performing Loan (NPL) terhadap Jumlah Kredit yang Disalurkan PT Bank Perkreditan Rakyat Mitra Riau (20112015). Jurnal Akuntansi Dan Ekonomika, 9(1).

Ratnasari, N. (2016). Variabel - Variabel Yang Mempengaruhi Penyaluran Kredit Kepada Umkm Oleh Perbankan Di Indonesia Tahun 2011-2015. Jurnal Pendidikan Ekonomi (JUPE), 4(3), 1-10. 